\title{
Affairs of the heart: patients' personal constructions of a cardiac event and their effect on lifestyle change
}

\author{
EC McKibbin, MA, University of the Witwatersrand \\ KG Wilson, MA, University of the Witwatersrand
}

Every affection of the mind that is attended with either pain or pleasure, hope or fear, is the cause of an agitation whose influence extends to the heart (William Harvey, in Jordaan, 1994).

Each man contemplates in his own personal way the stream of events upon which he finds himself so swiftly borne (Kelly, 1955, p.3).

\section{Abstract}

The issue of why people do not always make appropriate lifestyle changes in response to a cardiac event has and continues to be of central importance to health practitioners. This paper addresses this issue from the perspective of the lived experience of persons who have suffered an acute myocardial infarction (AMI). The experiences of 10 persons admitted to the coronary care unit (CCU) of a
South African clinic were richly described, making use of the grounded theory methodology. These descriptions were then used as a basis for the development of a contextualist theory of the experience of heart attacks. A central feature of the results was that the disease was mainly attributed to stress by the participants. This was in contrast to the explanations offered by the medical profession, who attribute this more to other modifiable risk factors such as smoking, high blood cholesterol, high blood pressure, and lack of exercise. This tension between lay and professional constructions of the aetiology of the condition is deemed to be of import in the recovery process. The paper further alludes to the goodness of fit which exists between the proposed grounded theory and the personal construct theory of George Kelly. The importance of personal constructions of the event is then used as the basis for a proposed intervention process aimed at addressing the difficulties AMI patients' experience in making and sustaining lifestyle changes.

\section{Introduction}

It is well accepted that coronary heart disease (CHD) is largely a disease of lifestyle (Elford, et al. 1994; Steyn and Buch. 1992; Wyndham, 1982). A wealth of scientific evidence points to a concurrent reduction in morbidity and mortality with a reduction in the risk factors, giving overwhelming support to the importance of reducing risk factors in all patients with CHD (Suter, et al. 1996; Wood, 1996; Wood, et al. 1998).

The common idea is that changing one's lifestyle is simply dependent on following medical advice. When patients fail to follow this well-intentioned advice, discouragement may be experienced by medical personnel involved in that patients are perceived to not be receiving the full benefit of their treatment due to persistence of risk factors (Elford, et al. 1994; Eraker, et al. 1984). Over 450 publications confirm people's apparent disregard for their doctor's advice (Reichman, 1987). Despite this, recent literature confirms that risk factor management is an integral part of the optimal care of the patient with CHD (Fuster, 1996).

The idea that people make lifestyle changes in response to doctors' advice (if given) has long been considered naive. The nature of the relationship between behaviour and attitudes is complex, with numerous studies indicating, at best, spurious links between behaviour and attitudes. Furthermore, the idea that attitudes change significantly in response to pro- fessional advice, cannot be taken for granted.

The study described in this paper was primarily concerned with developing a psychological theory of the subjective experience of a heart attack. Furthermore it demonstrated how patients' constructions of cardiac events affected their subsequent recovery and motivation to make lifestyle changes. This is based on the widely-held view that perceptions of events importantly impact on the effect which such events have on people (Blumenthal, et al. 1982. Richardson, et al. 1987, Surridge, et al. 1984, in Frasure-Smith, et al. 1995; Carney, et al. 1997; Connell and Bennett, 1997; Ewart, et al., 1986, Mishel, 1980, Peel, et al. 1962, in Hawthorne, 1994; Keckeisen and Nyamathi, 1990; Kelly, 1955; Pick, et al. 1994; Silverstone, 1987). As a result of the above-mentioned focus on the constructed nature of the experience relating to cardiac events, this paper contributes uniquely by contextually exploring the participants' lived experiences of a cardiac event and how these constructions affected subsequent motivations to modify their lifestyles.

In order to reduce the high morbidity and mortality from coronary heart disease, it is necessary for people to make and sustain lifestyle changes, particularly after a cardiac event. Further to this, the study aimed to better understand why this is seldom done, and to suggest alternatives to better patient care. The issue of why people do not make lifestyle changes in re- 
sponse to doctors' advice, even though they may hold adaptive attitudes towards health, has been much debated within the literature. The biomedical model tends to underestimate the importance of people's own theories of a cardiac event, and how these influence subsequent management of the risk factors (Broome and Llewelyn, 1995; Schlebusch, 1996). A response to this dilemma has been the development of a series of models which seek to account for the complex nature of healthrelated behaviour. Some of the more commonly used models are: Health Belief Model (Becker, 1974), the Health Decision Model (Eraker, et al. 1984), Theory of Reasoned Action (Ajzen and Fishbein, 1977), Theory of Planned Behaviour (Ajzen, 1988), Protection Motivation Theory (Rogers, 1975), and the Health Action Process Approach (Schwarzer, 1992).

\section{Thinking beyond the social cognition models of health behaviour change}

Harris and Middleton (1995) characterise all of the above-mentioned models as being "social cognition models of health behaviour (p. 107)", in that they attempt to explain social behaviour in terms of cognitive processes. Health behaviour change is thus viewed almost exclusively from a cognitive perspective, in which individual decision-making processes are emphasised. These models are useful in that they identify central factors involved in decision-making around health behaviour. However. these models fail to take account of other crucial factors such as the subjective nature of the disease experience, economics, the importance of environmental context, and the role of language in influencing behaviour.

Although the social cognition models represent a progression away from unidimensional biomedically-based understandings of health behaviour change, they do not fully encapsulate a more holistic perspective as represented by the notion of the biopsychosocial approach. This notion has gained increasing acceptance within psychology over the last two decades, in that it argues that psychological phenomena should be understood in terms of their composite biological, psychological and social dimensions. Furthermore the biopsychosocial approach is congruent with the World Health Organisation's (1958, in Stanhope and Lancaster, 1984, p. 32-33) definition of health as not merely constituting the absence of disease, but a complete state of physical, psychological and social well-being.

Although this paper does not attempt to provide a comprehensive biopsychosocial explanation of the experience of heart attacks, it does take into account the importance of subjective experience in health behaviour change. It is our contention that this is important because this type of information cannot readily be accommodated within the traditional social cognition models.

\section{The heart attack study}

This paper presents findings and issues relating to a grounded theory investigation of the experiences of persons diagnosed as having acute myocardial infarction (AMI). The persons who participated in the study had all been admitted to the coronary care unit of a well-established private clinic in Johannesburg,
South Africa. In keeping with the commitment of qualitative research to context, authenticity, and cultural meaning, purposive (non-random) sampling was employed (Durrheim, 1999; Neuman, 1997). Given the infrequent nature of admissions relating to AMI, it was decided that every person admitted to the coronary care unit from February 1998 onwards until there was a total of ten participants, would be interviewed. The intensive nature of data collection, and more especially data analysis in grounded theory, limited us to ten persons. We could have chosen to interview fewer, but wished to have a data pool which would contribute meaningfully in the later theory-building stages of the project. It was necessary to exclude five persons who were either scheduled for immediate surgery, who were adjudged to be too ill, or who were not sufficiently fluent in English. Each of the participants were interviewed between February and June 1998.

According to Pidgeon and Henwood (1996) the data collection and data analysis phases of grounded theory are iterative and often occur simultaneously. More practically, this meant that data analysis began at the same time as data collection, but that as the study developed the type of analyses being conducted became more complex in response to the emerging "heart attack" theory. As the theory developed, theoretical sampling data was also collected by means of two semi-structured interviews and two focus groups (Glaser and Strauss, 1967; Pidgeon, 1996).

\section{Constructing healthy people}

George Kelly (1955) proposes the view that all people are 'scientists' in that we seek to describe, explain, predict and control events within our experience. Consequently, we will develop construct systems that enable us to more effectively predict events. In making sense of the thoughts, feelings and actions of persons, Kelly advocated a position of constructive alternativism. This position is based on the assumption that "all of our present interpretations of the universe are subject to revision or replacement (Kelly, 1955, p.15)". In this way we attempt to construe our world, and in so doing try to interpret and explain it. This is achieved cognitively by means of deductions, interpretations, conclusions, etc. This "private logic" (Phares, 1991, p.175) is at the heart of what Kelly refers to as personal construct theory (PCT).

The importance of the construction of experience is not adequately accounted for in the discourses related to the social cognition models. The healthy-unhealthy construct as well as being dichotomous, is also permeable and pre-emptive. It seems that it was very difficult for any of the participants in the study to characterise themselves as being "unhealthy" per se. Furthermore, as a result of the permeability of the construct "healthy", most lifestyles could be described by the concept at specific times.

In attempting to describe the experience of AMI we have adopted a two-stage approach. Firstly, descriptions available from the literature will be discussed. Secondly, and building on the first step, we will then go on to describe how the participants themselves experienced the event. The reason for adopting this strategy is to acknowledge the extent to which AMI patients do not develop understandings of what they have gone through independently of forms of knowledge associated with the professional culture of medicine. 


\section{The experience of an Acute Myocardial Infarction (AMI) - some notes from the literature}

The crisis that ensues when people's lives are threatened by a cardiac event or intervention is an extremely stressful experience wherein they describe a range of intense negative psychological and physical experiences, and a sense of shattered identity (Carney, et al. 1997; Connell and Bennett. 1997; Crowe, et al. 1996; Fielding, 1991; Ford, 1989; Gross, 1994; McNamee, 1992; Wilde McCormick, 1984).

The first response often appears to be a reactive "why me?" followed by an attributional search to regain some sense of control (Cowie, 1976; Ducette and Keane, 1984; Frazier and Garvin, 1996; Jacobsen, et al. 1992; Scherk, 1992). Avoidance strategies are also employed in order to assist in coping (Johnson and Morse, 1990; Lawrence and Lawrence. 1987/8; Lowery, et al, 1992; Rudy, 1980; Wiklund, et al, 1985). It should be noted that at least one group of researchers (Jacobsen et al., 1992) consider evidence of this strategy to be inconclusive. Cowie (1976) suggests the tendency to relate the history of events leading up to the hospitalisation as a means of structuring events in such a way as to reduce feelings of anxiety relating to the unpredictable nature of the event.

Patients' realities are structured to fit with their perceptions (Kelly, 1950; Sykes, 1994). The most common attribution for the event is 'stress'- either at work or home (Rudy, 1980). This attribution plays a complex role and contributes to increasing anxiety and decreasing self-blame. In this way the need to address medically accepted risk factors is also overlooked (Faller, 1990). Meanings from past events help 'normalise' the present and reconstruct the future (Cowie, 1976).

The process of regaining a sense of control continues over the next few months, during which period losses are mourned (Gross, 1994) and priorities and identities re-structured (Johnson and Morse, 1990; Wiklund, et al, 1985; Younger, 1991).

According to West (1998) there is a paucity of valid studies that link increased morbidity and mortality to psychological distress, though many researchers consider these factors to be implicated (Cay, 1972. Lloyd, 1983, in Pell, 1997; Connell and Bennett, 1997; Scherk, 1992). However, increased morbidity and mortality contributed to by the persistence of medically accepted risk factors is well substantiated (Digenio and Joughin, 1997; Sawa, et al, 1991; Suter, et al, 1996; Wood, 1996; Wood, et al, 1998). Addressing the psychological distress contributes to regaining a sense of control. This includes a growing awareness of the need for some sort of lifestyle change (Connell and Bennett, 1997; Fielding, 1987; Ford. 1989; Frasure-Smith, et al, 1993; Gross, 1994; Linden, et al, 1996; Livneh and Sherwood-Hawes, 1993; Moser and Dracup, 1995; Murray, 1989; Raleigh and Odtohan, 1987; Scherk. 1992; Schindler, et al, 1989; Sykes, 1994; Thompson, et al, 1996). Necessary lifestyle changes include a healthy diet, exercise, cessation of smoking and so on (Ornish, 1990). However, international and local studies abound with evidence of these remaining relatively unaddressed (McKibbin, 1994). If changes are attempted, they are not sustained (McSweeney, 1993). Attributions, percep- tions, co-constructions, defences have been considered influential for over six decades (Ben-Sira and Eliezer, 1990; Carney, et al, 1997; Connell and Bennett. 1997; Cowie, 1976; Faller, 1990; Fielding, 1987; Fleury, 1991, 1996; Frasure-Smith. et al, 1995; Frazier and Garvin, 1996; Johnson and Morse, 1990; Ladwig, et al, 1992; Lozano, et al, 1989; McSweeney, 1993; Pell, 1997; Pick, et al, 1994; Pill and Stott, 1982; Scherk. 1992; Silverstone, 1987; Thompson, 1995). Despite this, little is done to assist people in their plight, particularly in our healthcare system (Digenio and Joughin, 1997; Fielding, 1987; Sykes, 1994) and people's perceptions go largely ignored (Frazier and Garvin. 1996; Guiry, et al, 1987). Thus, the period of dependency at the time of the event or intervention offers a 'window of opportunity' to assist people at this time (Emmons and Goldstein. 1992. p. 262).

\section{Personal constructions of the heart attack experience}

The story of how the participants made sense of their cardiac event traces how they moved through the stages of struggling to acknowledge that they were experiencing an AMI, disbelief, shock, excruciating pain, anxiety regarding their immediate survival and longer-term fears of its implications. Throughout these stages, they progressively made sense of the event as they experienced emotions ranging from denial, confusion, remorse, disbelief, shock, anger, disappointment, grief, frustration, guilt and fear (cf. Johnson and Morse, 1990; Lawrence and Lawrence, 1987/8; Lowery, et al, 1992; Rudy, 1980; Wiklund, et al. 1985).

The path to hospitalization was guided by the experience and intensity of the pain, with many participants going to hospital only when the pain was intolerable. As the pain increased in intensity, participants were involved in a complex decisionmaking process relating to what their response to this pain should be. The pain was seen as a harbinger of possible death. In the words of one participant "I was waiting to - upstairs for the angels to start singing...well I thought this was one of those things - either you make it or you don't. Your number's up - so it be."

Though there were different responses, most perceived the severity realistically. They were stunned by the 'below-thebelt' nature of the event, describing it in detail. They sought for reasons as to "why me?", struggling to give explanations where sometimes there were none. Throughout the period of hospitalisation they sought attributions, and affirmed stress to be a major one ( $c f$. Rudy, 1980). They acknowledged risk factors for CHD, but believed that these generally did not apply to them personally, or totally.

Participants acknowledged some kind of change was necessary, but this pertained mostly to stress. In "storying", they selected aspects of their lived experiences and organised events in such a way as to give meaning to their experiences (White and Epston, 1990).

On experiencing increasing intensity of pain, the participants were confused as to the cause. They described in detail events (mowing the lawn, cycling, rushing to go out. and so on) leading up to the onset of pain. Their initial sense-making strategy 
sometimes included attributing the pain and related symptoms to a previously occurring condition which had been successfully treated. As one participant said: "About 04 h30 on Friday the $13^{\text {th }}$ I woke up with some mild chest pains which I thought were indigestion because I've had gastritis and I'm on Lanzor tablets on a maintenance basis." Similarly, another participant remarked: "Well, on Friday I was mowing the lawn. I've got some gastric problems you know. And as I was mowing the lawn I felt something pressing me here (indicating his chest), but I just kept on going". Another person who had previously experienced a myocardial infarction (MI) and subsequent cardiac intervention (in the form of percutaneous transluminal coronary angioplasty(PTCA)) attributed the onset of pain to indigestion - "Fortunately, I didn't tell the wife and kept quiet for a while, and took half an anisec and try and dissolve it...I got dressed to do my normal pottering around, as I always do, and I felt this pain is getting - still there. And it was sore!"

A feature of the heart attack was the nature and meaning of the experience of pain. This pain was spoken about openly, but it does seem that the significance of the experience is sometimes not fully acknowledged. "'Ell it was terrible! Really, it was terrible! It was terrible!" The participant went on to say later in the interview "Terrible! No this is terrible! I tell you what, my biggest enemy I wouldn't let him have a heart attack. It's terrible! Really it is!"

The sentiments expressed in the following quotations demonstrate the difficulty which people experience in attempting to put into words the meaning of their pain. "I had terrible pain on the chest - it was agonising! And all I remember, I was saying please help me! Please help me!" "Ooh, but the pain is unbelievable." "But this one has shook me, it shook me badly. I never realised you could come that close to death, as what I did with this one." The participant here gives an example of the sometimes anxiety-provoking thoughts and feelings associated with the contemplation of mortality. The quotation captures the central feature of participants' talk about death - shock and disbelief that it could happen to them. Similarly another participant stated: "I' $m$ still in shock because I never thought it could happen to me. I thought I was on my way out! You think you can control your life".

Another issue here is that the expression of the belief that exercising control over lifestyle of necessity means that mortality is somehow "managed". In addition to all the participants being shocked that this could happen to them, there was also a widely held belief that they were not the "type of person" to whom it should happen. This has direct relevance to the notion of lifestyle change. Generally held views of subjectivity associated with lifestyle change tend to centre around the concept of the person as a "unitary rational subject". The lived contradictions of the participants' lives were often smoothed over. Participants did not actually view themselves as living unhealthy lifestyles. They offered up modes of living, such as "walking a few k's every day" which could be associated with health. From this it can be seen that lifestyle change can only be made with great difficulty, if the person attempting to make them does not feel that they are warranted. The irony here is that it is a constricted conception of personal identity which presents the problem and not more common-sense explanations such as "lack of motivation", "sloth", and so on. This tension can be seen in the following quotation: "Me? A heart attack? Where could I ever have - Could it be a minor or a major - Never a heart attack! And it didn't need - It's never even entered my head because I'm a perfectly healthy person." The important issue here is that the participants perceived themselves as being "healthy", and indeed one would not really expect anyone to describe themselves as being "unhealthy",

The behaviour of people is best understood by focussing on present constructions. It follows that any expressed intentions to make lifestyle changes would pertain to stress. Several of the participants expressed such ideas: "I think that I've got to realise that I've got to now look after me, and my wife after me - where I've been trying to look after everybody else's problems. I've got my own problems that I have to look after. More carefree type of life".

Stress was described in relation to job and personal circumstances. The hard-driving, perfectionist nature of the patient and/or his or her boss were believed to contribute to CHD, as did the sense of unfairness of having been taken advantage of. People described being "stretched beyond the limits".

Financial pressure impacted on family circumstances which they believed contributed to CHD. These life events often included loss of some sort (a spouse, a job), and the course their lives took as a result, sometimes resulting in disappointing or anxiety-provoking relationships.

Follow up meetings with participants confirmed a continuation of dominant issues, aggravated by impaired health. This not only affected motivations for lifestyle changes, but often the coping strategies they used were the very factors needing to be modified. Even at this stage participants continued to seek out other causes of the event.

The participants were apprehensive, but hopeful that this event could act as a springboard for better things to come. "But...in a sense it's bad pains and that, but it may be the best thing in the end. It's a warning - a waming...But I feel that something good is going to come out of it..."

\section{A grounded theory of heart attacks}

George Kelly's (1955) idea of people being scientists and therefore seeking to describe, explain, predict and control their lifeworlds, relates to grounded theory's concern with the generation of context-specific theory. In a reflexive manner we, as researchers, were seeking to make sense of the experiences of the "other" - in this case, persons who experienced heart attacks. Thus, some of the separation between "researcher" and "researched" was called into question. Furthermore, the grounded theory methodologist and their "subjects" are involved in ostensibly the same process of meaning-making. This, once again, hints at the goodness of fit between PCT, as the theoretical framework, and grounded theory, as the methodology. The grounded theory then, becomes an expression of the manner in which personal constructs are configured in a particular context.

The participants" psychological processes were "channelized" 
by present and future anticipations based on recurrent themes in their lives. 'Stress' as the superordinate concept, encompassed themes of immediate stress (which precipitated the event), chronic job stress (which lay the foundations for the event) and difficult or painful personal circumstances (which compounded the effects). Thus, stress was overwhelmingly construed as the "obvious" cause of the cardiac event.

At this stage the participants, though angry at the unfairness of it all, considered they had been given a second chance. Motivations to make lifestyle changes pertained to stress, not diet, lack of exercise, being overweight, smoking, high blood pressure, and other traditional risk factors.

PCT accommodates a variety of construction systems, as well as the possibility of extending constructs. It offers opportunities for reflection and reconstruction. There are many indications from the afore-mentioned dialogue between Kelly's ideas and the participants' stories, that this stage of the patient's treatment presents a 'window of opportunity' for an intervention to facilitate reconstructions of past events.

Drawing on the work of White and Epston (1990) the present study was able to re-interpret why people with CHD do not readily modify their risk factors and make relevant lifestyle changes. Kelly (1963) claims it is the meaning given to an event that is influential, not the event itself. Personal meanings are the basis of individual theories through which current experiences are filtered and interpreted, anticipated and responded to, as a consequence of anticipations. Experiencing a cardiac event, and attributing personal meanings to it made the participants' subsequent motivations understandable and predictable. Kelly's (1963, p. 46) entire theory is based on this concept, expressed by the Fundamental Postulate which states, 'A person's processes are psychologically channelized by the ways in which he anticipates events'. As stated by the participants; "I'm sure stress is the cause;...my lifestyle is under pressure;...I put it down to stress;...I think stress in my business;...it comes to trying to stretch myself;...it's possibly more stress than anything else;...I think pressure of work because I am a perfectionist".

Even the most unusual of events are anticipated in terms of replicative past themes, as stated in Kelly's (1963, p. 56) 'Organization Corollary': 'Each person characteristically evolves, for his convenience in anticipating events, a construction system embracing ordinal relationships between constructs'. The participants' personal constructions and the way they were organised were developed to make sense of the event and transcend any future contradictions. In their search for meaning, the participants looked at choices in multidimensional ways, and then selected, or did not select, certain constructs according to their repetitive nature within their lived experience. This decision-making cycle is likened by Kelly (1955, pp. 514-517) to mounting a horse which you can't then ride off in all directions.

How 'stress' affected the participants' lives differed, and this demonstrated the permeability of the 'stress' construct. Progressive variations took place independently as participants related deeper personal meanings of 'stress'. The 'stress' construct supported these alterations and thus qualified as a theory (Kelly, 1963). Theoretical limitations are imposed in Kelly's (1963, p. 77) Modulation Corollary, which states, 'The variation in a person's construction system is limited by the permeability of the constructs within whose range of convenience the variants lie'. It would be a truism to state that oftentimes life is difficult . Superimpose a forceful, underhand and unexpected blow such as a cardiac event, and the participants are left seeking new constructions of the event to make subsequent anticipations more realistic (Kelly, 1963).

\section{A contextually-based intervention model}

The theory that emerged from the developing constructs affirmed that stress, past, present and future, played a major role in contributing to the cardiac event. This, in turn, contributed insights into how necessary lifestyle changes were perceived in the light of such theories.

The meaning given to the cardiac event was intensely personal, and participants experienced a sense of indignation at the injustice of it all. According to Kelly, if we really want to play a part in helping people change, we need to understand and accept their different constructions of a cardiac event, as stated in the Sociality Corollary (Kelly, 1963, p. 95), 'To the extent that one person construes the construction process of another, he may play a role in a social process involving the other person'.

Kelly (1955) affirms, the focus of convenience which we have chosen for our own theory-building efforts is the psychological reconstruction of life. We are concerned with finding better ways to help a person reconstrue his life so that he need not be the victim of his past (p.23).

Confirmation of 'stress' as the dominant construct may lead people into more reconstruing than disconfirmation, in order to maximise the extent to which the world can be predicted (Kelly, 1966, in Bannister, 1970), further directing their motivations. However, it has been shown that 'stress' is a permeable enough construct to accommodate competing constructions.

\section{Step 1: Telling the story}

The telling of the story is deemed to be a basic yet essential first step in that a person who has experienced an AMI will most probably be struggling to make meaning of the event. All attempts at meaningful lifestyle change are based on the centrality of the story within the lived idiosyncratic experience of the "AMI patient." By story we mean a subjective telling of what happened and how that event was interpreted. The relationship between the story of the event and the event itself is complex. The story does not merely represent that which has happened, but, we would argue, is also in some way constitutive of conditions of possibility such as change and/or recovery. Furthermore the story also reflects aspects of the identity of the story-teller. According to White (1995) we live by the stories that "we have about our lives, that these stories actually shape our lives, constitute our lives, and that they "embrace' our lives (p.14)."

It was evident in the interviews and the focus groups that participants wished to engage in a detailed discussion of their 
experience of the AMI. It was also evident that the limited time available was not sufficient for an adequate telling of the story. It seemed that it was difficult for participants to move on to a discussion of lifestyle change until they had adequately and spontaneously described/worked through the experience.

One of the aims of this initial step is to facilitate persons describing their understanding of the cause/s of the AMI. Frazier and Garvin (1996) identified finding cause as a key theme in the naturally occurring conversations of MI patients. The therapeutic value of such "exploration of cause" - type conversations cannot be underestimated, as the search for attributions is an important aspect of the "working through" of the event. Stated differently, the aspects of the event which have the capacity to undermine or threaten the identity of the MI patient need to be "made sense of" in an experience-near manner. Similarly, Johnson and Morse (1990) identified making sense as an important part of the process of coming to terms with what has happened. In discussing possible causes, sense is made. This is not a finite process, in that the life-threatening nature of the MI means that people who experience it will probably not just 'get over it'.

The "exploration of cause" conversation would also involve a deconstruction of the notion of "risk factors", the idea being that lack of exercise, smoking, and so on, are not only "risk factors" but also behavioural choices which people have made. Smoking, quite apart, from being an obvious health risk, could also be a method of coping. The acknowledgment of the fact that lifestyle choices such as smoking or lack of exercise are not aberrant, per se, but also have "gains" for the persons engaging in such behaviour, is seen to be an important step on the journey to successful lifestyle change. Within the study one participant remarked: "Smoking - I'm not going to do [that]! I think when I get out of here it will be very hard, but I've never had to smoke in company. I smoke more by myself because I was using it as a companion."

For Frazier and Garvin (1996) a further theme that emerged from the naturally occurring conversations of MI patients was that of acting normally (p.30). This theme incorporated "participants' attempts to preserve their normal patterns or habits, to resume normal activities and to maintain accustomed levels of personal control (p.30)." Keeping this in mind, it can be seen that there is a fundamental problem in traditional attempts at bringing about lifestyle change in that they do not acknowledge the extent to which people have an investment in maintaining their usual lifestyle. In terms of this, it does not seem surprising that calls from medical personnel to "just change" are often not heeded. Indeed, paradoxically, if MI patients were to make suggested lifestyle changes they could in fact be undermining their own sense of self.

Changing one's lifestyle is also stressful, in that smoking could be an attempt to deal with stress in the first place, so that when a person stops smoking it has the obvious, but experiencedistant effect of prolonging life. The other side of this lifestyle change could be that the daily felt experience of stress is heightened. This becomes even more important, if we take into account the 'privileged' nature of stress in accounting for the cause/s of the MI.

\section{Step 2: Retelling the story}

The aim of the first step is to facilitate the telling of peoples' stories. In doing this the general therapeutic imperative of "working through" is addressed by means of exploring cause and generally attempting to make sense of what has happened. The focus in the first step then is on generating comprehensive descriptions of what has happened. In the second step the focus moves to these descriptions being taken up and deconstructed, by means of the story being retold.

The "retelling the story" step is made up of the following components:

Generating rich and experience-near descriptions of the person's lifestyle - This should be done in a non-judgmental and value-neutral manner. We feel that it is important for the person's lifestyle to be acknowledged, as well as to be accurately understood.

Remembering change - This involves richly describing times in the person's past when they have changed an aspect of their lifestyle. This would also include the telling of how that was accomplished. This sets the scene for the development of an alternative account of the MI patient's ability to make changes. White (1990) posits that in identifying previously neglected accounts "persons can be encouraged to engage in performances of new meaning in relation to these (p.41)".

Separating the act of change from the identity of the person who wishes to make changes - Making meaningful lifestyle changes is a difficult process. When MI patients attempt to make changes, and are somehow unable to, it is likely that they may feel dismayed and become discouraged from persevering with their plans to make and sustain changes. As a result of this, it is important that the person is in a position to take a stand against the problem without taking a stand against her/ him self. This is achieved by means of engaging the person in an 'externalising conversation' ( $c f$. White, 1990). Here the problem and its influence is clearly defined, and then the person's relationship to the problem is discussed, in order that possibilities of action and change can be explored.

Deconstructing change - Change is often viewed as a simplistic process in which a person merely 'decides' to change and then 'just does it'. Making sustained and meaningful lifestyle changes is a difficult and ongoing process. This fact needs to be acknowledged and taken seriously by health care workers. It is therefore useful to join with the patient in some discussion of the meaning and value of change. The idea here is to locate the change process within the terms of reference of the patient her/himself. In this way 'change' is constructed not as a rarified goal, but rather as a series of steps which fit with the person's plans for his or her life after the AMI.

Developing and persisting with the plan for change - The important point is not to try to persuade or cajole the patient into making lifestyle changes but rather to fully understand her/his preferred ways of living. This is very important as it links the cardiac event to the person's history, and in so doing asks open questions about how the future could be. This can be also be furthered by identifying what are seen as barriers to change, and anticipating how these may influence the plan for change. 


\section{Conclusion}

The 'window of opportunity' that exists is to offer patients in hospital with a cardiac event or intervention, an opportunity to explore personal constructions, particularly 'stress' within a group context.

The findings indicate that people will not make adequate lifestyle changes in response to a cardiac event if it is not part of their construal systems. They are motivated to make changes according to their psychological processes which are "...channelized by the ways in which [they] anticipate events (Kelly, 1963, p. 46)". How they make sense of a cardiac event has far-reaching implications for subsequent motivations to alter lifestyle.

The participants attributed 'stress' to be the main contributor to the cardiac event. This construct spanned many areas of their lives, and had particular meaning for each individual. This became their dominant story, based on present constructions of past events and future anticipations. It also predicted motivations for successful lifestyle changes.

The period of hospitalisation offers a 'window of opportunity' to harness the motivations towards better lifestyle management, and provides an opportunity for reconstructions of the cardiac event, and in so doing challenges the dominant, but unhelpful stress story. In order to better meet the needs of cardiac patients, greater attention must be given to their personal theories

Personal Construct Theory provides a valuable tool to reflect on past and present constructions and future anticipations, all of which are open to reconstructions in the quest for better alternatives. It is proposed that patients be offered the opportunity, prior to discharge, to share their reconstructions and explore alternate possibilities in a supportive group setting. In so doing, they become empowered to examine choices, based on values and goals. Changing risk factors can then be explored in this context. In this way we can continue to "...break links in the chain of causation [of coronary heart disease] - at every accessible link in the chain (Stamler, 1985, p. 1055)".

\section{References}

ADSETT, CA \& BRUHN, JG 1968: Short-term group psychotherapy for post-myocardial infarction patients and their wives. The Canadian Medical Association Journal. 99, $12,577$. 584 .

AJZEN, I 1988: Attitudes, personality and behaviour. Milton Keynes: Open University Press.

AJZEN, I \& FISHBEIN, M 1977 : Attitude-behaviour relations: a theoretical analysis and review of empirical research Psychological Bulletin. 84, 888-918.

BANNISTER, D ed 1970: Perspectives in Personal Construct Theory. London: Academic Press.

BECKER, HM 1974: The health belief model and personal health behaviour. Thorofare, NJ: Slack.

BEN-SIRA, Z \& ELIEZER, R 1990: The structure of readjustment after heart attack. Social Science Medicine. 30, 5, 523-536.

BROOME, A \& LLEWELYN, S eds 1995 : Health Psychology: Processes and applications $2^{\text {nd }}$ Ed. London: Chapman and Hall.

CARNEY, RM; FREEDLAND, KE; SHELINE, Y \& WEISS, ES 1997: Depression and coronary heart disease: a review for cardiologists. Clinical Cardiology. 20, 196-200.

CONNELL, H \& BENNETT, P 1997: Anticipating levels of anxiety and depression in couples where the husband has survived a myocardial infarction. Coronarv Health Care. 1, 1, 2226.

COWIE, B 1976: The cardiac patient's perception of his heart attack. Social Science and Medicine. 10, 87-96.

CROWE,JM; RUNIONS, J; EBBESEN, LS; OLDRIDGE, NB \& STREINER, DL 1996: Anxiety and depression after acute myocardial infarction. Heart and Lung. 25, 2, 98-107.

CRAIB, 1 1994: The importance of disappointment. London: Routledge

DIGENIO, AG \& JOUGHIN, HM 1997: Should all cardiac patients be offered the choice of cardiac rehabilitation? Cardiovascular Journal of Southern Africa (SAMJ Supplement 3), C136-137; C142-143.

DURRHEIM, K 1999: Research design. In M. Terre Blanche \& K. Durrheim (Eds.) Research in practice: applied methods for the social sciences. Cape Town: University of Cape Town Press.

ELFORD, RW; YEO, M; JENNETT, PA \& SAWA, RJ 1994: A practical approach to lifestyle change counselling in primary care. Patient Education and Counseling. 24, 175-183

EMMONS, KM \& GOLDSTEIN, MG 1992: Smokers who are hospitalised: a window of opportunity for cessation interventions. Preventive Medicine. 21, 262-269.

ERAKER, SA; KIRSCHT, JP \& BECKER, MH 1984: Understanding and improving patient compliance. Annals of Internal Medicine. 100, 258-268.

FALLER, H 1990: Coping with myocardial infarction: a cognitive-emotional perspective. Psychotherapv and Psvchosomatics. 54, 8-17.

FIELDING, R 1987: Patients' beliefs regarding the causes of myocardial infarction: implications for information giving and compliance. Patient Education and Counseling. 9. 121-134.

FIELDING, R 1991: Depression and acute myocardial infarction: a review and reinterpretation. Social Science Medicine. 9, 1017-1027.

FLEURY, J; KIMBRELL, LC \& KRUSZEWSKI, MA 1995: Life after a cardiac event: women's experience in healing. Heart and Lung. 24, 474-482. 
FLEURY,J 1996: Wellness motivation theory: an exploration of theoretical relevance. Nursing Research. 45, 5, 277-284.

FORD, JS 1989 : Living with a history of a heart attack: a human science investigation. Journal of Advanced Nursing. $14,173-179$.

FRANKL, VE 1969: The will to meaning. Foundations and applications of Logotherapy. New York: Plume.

\section{FRASURE_SMITH, N; LESPE'RANCE,F \& TALAJIC, M 1993}

: Depression following myocardial infarction: impact on 6month survival. Journal of the American Medical Association. $270,1819-1825$.

FRASURE_SMITH,N; LESPE'RANCE,F \& TALAJIC,M 1995

: The impact of negative emotions on prognosis following myocardial infarction: is it more than depression? Health Psychology. 14, 5, 388-398.

FRAZIER, SK \& GARVIN, BJ 1996 : Cardiac patients' conversations and the process of establishing meaning. Progress in Cardiovascular Nursing. 11, 4, 25-34.

FUSTER, V 1996 : Matching the intensity of risk factor management with the hazard for coronary disease events. Paper presented at the XVIIIth Congress of the European Society of Cardiology, $25^{\text {th }}$ August, Birmingham, UK.

GLASER, BG \& STRAUSS, AS 1967 : The discovery of grounded theory. Strategies for qualitative research. Chicago: Aldine Publishing Company.

GOLAN, N 1981 : Passing through transitions: a guide for practitioners. New York: Free Press.

GROSS, SJ 1994 : The process of change: variations on a theme by Virginia Satir. Journal of Humanistic Psychology. 34, 3.87-110.

\section{GUIRY,E; CONROY,RM; HICKEY, N \& MULCAHY, R 1987}

: Psychological response to an acute coronary event and its effect on subsequent rehabilitation and lifestyle change. Clinical Cardiology. 10, 256-260.

HARRIS, P \& MIDDLETON, W 1995 : Social cognition and health behaviour. In D. Messer \& C. Meldrum (Eds.) Psychology for nurses and health care professionals. London: Prentice Hall.

HAWTHORNE, MH 1994 : Gender differences in recovery after coronary artery surgery. Image: Journal of Nursing Scholarship, 26, 1, 75-80.

HUTCHINSON, SA 1984 : Creating meaning out of horror. Nursing Outlook. 32, 2, 86-91.

JACOBSEN, BS; LOWERY, BJ \& MCCAULEY, K 1992 : Why me? Causal thinking, affect and expectations. Journal of Cardiovascular Nursing. 6, 2, 57-65.

JANOFF-BULMAN, R \& WORTMAN, CB 1977 : Attributions of blame and coping in the 'real world': severe accident victims react to their lot. Joumal of personality and social psvchology. 35. 2. 351-363.

JOHNSON, JL \& MORSE, JM 1990 : Regaining control: the process of adjustment after myocardial infarction. Heart and Lung. 19.2. 126-135.

JORDAAN, G 1994 : Psigiatriese faktore in kardiologiese toestande. Continuing Medical Education Journal. 12, 9, 1157 1165 .

KECKEISEN, ME \& NYAMATHI, AM 1990 : Coping and adjustment to illness in the acute myocardial infarction patient. Journal of Cardiovascular Nursing. 5, 1, 25-33.

KELLY, GA 1955 : The psychology of personal constructs, vol I, A theory of Personality. New York: Norton and Company.

KELLY, GA 1963 : A theory of personality. The psychology of personal constructs. New York: Norton and Company.

LADWIG, KH; LEHMACHER, W; ROTH, R; BREITHARDT, G; BUDDE, T \& BORGGREFE, M 1992: Factors which provoke post-infarction depression: results from the post-infarction late potential study (PILP). Journal of Psychosomatic Research. 36, 723-729.

LAWRENCE, SA \& LAWRENCE, RM 1987/8 : Helping patients cope with the stress of myocardial infarction. Nursing Forum. 23, 3, 92-100.

LEVINE,J; WARRENBURG,S; KERNS, R; SCHWARTZ, G; DELANEY, R; FONTANA, A; GRADMAN, A; SMITH, S; ALLEN, S \& CASCIONE, R 1987 : The role of denial in recovery from coronary heart disease. Psychosomatic Medicine. 49, 2, 109-117.

LINDEN, W; STOSSEL, C \& MAURICE, J 1996 : Psychosocial interventions for patients with coronary artery disease. Archives of Internal Medicine. 156, 745-752.

LIVNEH, H \& SHERWOOD-HAWES, A 1993 : Group counseling approaches with persons who have sustained myocardial infarction. Journal of Counseling and Development. 72, 57-61.

LOWERY, BJ; JACOBSEN, BS; CERA, MA; MCINDOE, D; KLEMAN, M \& MENAPACE, F 1992 : Attention versus avoidance: attributional search and denial after myocardial infarction. Heart and Lung. 26, 6, 523-528.

LOZANO, M; CARCEDO, C; ARTIGAO, R; HUERTAS, D; O'NEILL OF TYRONE, A; PELEGRIN, C; MAROTO, JM \& JORDA, L 1989 : Psychiatric care of coronary artery disease in a cardiac rehabilitation unit. Psvchotherapy and Psvchosomatics. 52.80-87.

MCKIBBIN, EC 1994 : An analysis of the risk factors for coronary heart disease in patients aged 55 and younger with proven heart disease. Curationis. 17, 3, 51-56.

MCNAMEE, 1992 : Reconstructing identity: the communal construction of crisis. In S. McNamee \& K. Gergen (Eds). 
Therapy as a social construction. London: Sage Publications.

MCSWEENEY,JC 1993 : Making behavior changes after a myocardial infarction. Western Journal of Nursing Research. $15,4,441-455$.

MOSER, DK \& DRACUP, K 1995 : Psychosocial recovery from a cardiac event: the influence of perceived control. Heart and Lung, 24, 4, 273-280.

MURRAY, PJ 1989 : Rehabilitation information and health beliefs in the post-coronary patient: do we meet their information needs? Journal of Advanced Nursing. 14, 686-693.

NIR, Z \& NEUMAN, L 1990 : Motivation patterns, selfesteem, and depression of patients after first myocardial infarction. Behavioral Medicine, Summer, 62-66.

ORNISH, D 1990 : Reversing heart disease. London: Century.

PELL, J 1997 : Cardiac rehabilitation: a review of its effectiveness. Coronary Health Care, 1, 8-17.

PHARES, EJ 1991 : Introduction to personality third edition. New York: Harper Collins.

PETRIE, KJ; WEINMAN,J; SHARPE, N \& BUCKLEY,J 1996 : Role of patients' view of their illness in predicting return to work and functioning after myocardial infarction: longitudinal study. British Medical Journal. 312, 1191-1194.

PICK, B; MOLLOY, A; HINDS, C; PEARCE, S \& SALMON, P 1994 : Post-operative fatigue following coronary artery bypass surgery: relationship to emotional state and to the catecholamine response to surgery. Journal of Psychosomatic Research. 38, 6, 599-607.

PIDGEON, N 1996 : Grounded theory: theoretical background. In J.E. Richardson (Ed.) Handbook of qualitative research methods for psychology and the social sciences. Leicester: BPS Books.

PIDGEON, N \& HENWOOD, K 1996 : Grounded theory: practical implementation. In J.E. Richardson (Ed.) Handbook of qualitative research methods for psychology and the social sciences. Leicester: BPS Books.

PILL, R \& STOTT, NCH 1982 : Concepts of illness causation and responsibility: some preliminary data from a sample of working class mothers. Social Science and Medicine. 16, 4352.

RALEIGH, E \& ODTOHAN, B 1987 : The effect of a cardiac teaching program on patient rehabilitation. Heart and Lung. 16, 3,311-317.

REICHMAN, LB 1987 : Compliance in developed nations. Santa News. Nov, 4-5.

RICE, V; HILL; MULLIN, MH \& JAROSZ, P 1992 : Preadmission self-instruction effects on postadmission and postoperative indicators in $\mathrm{CABG}$ patients: partial replication and extension. Research in Nursing and Health. 15, 253-259.

ROGERS, RW 1975 : A protection motivation theory of fear appeals and attitude change. Journal of Psychology. 91, 93114.

RUDY, EB 1980 : Patients' and spouses' causal explanations of a myocardial infarction. Nursing Research. 29, 6, 352-356.

SAWA, RJ; JENNETT, P \& ELFORD, RW 1991 : Reducing the risk of coronary artery disease: helping patients change. Canadian Family Phvsician. 37, 651-654.

SCHERK, K 1992 : Coping with acute myocardial infarction. Heart and Lung. 21, 327-334.

SCHINDLER, BA; SHOOK, J; \& SCHWARTZ, GM 1989 : Beneficial effects of psychiatric intervention on recovery after coronary artery bypass graft surgery. General Hospital Psychiatry. 11, 358-364.

SCHLEBUSH, L 1996: Health Psychology in South Africa: an introduction. South African Journal of Psychology. 26, 1, 13.

SCHWARZER, R 1992 : Self-efficacy in the adoption and maintenance of health behaviours: Theoretical approaches and a new model. In R. Schwarzer (Ed). Self-Efficacy: Thought Control of Action. Washington: Hemisphere.

SILVERSTONE, PH 1987 : Depression and outcome in acute myocardial infarction. British Medical Journal. 294, 219-220.

STAMLER, J 1985 : Coronary heart disease: doing the "right things". New England Journal of Medicine. 312, 16, 